\title{
The mystery of the missing oil plume
}

\section{Confounding reports seed confusion over long-term effects of the spill.}

Now you see it, now you don't. According to news reports last week, the plume of oil in the depths of the Gulf of Mexico is no more. But just days earlier, the subsurface plume had been proclaimed a long-lived menace.

The baffling stories about the fateful Deepwater Horizon plume spring from two studies published in Science ${ }^{1,2}$ last month, which have sparked debate among scientists, along with calls for better communication between those studying the spill.

If the plume is actually lingering, animals from shrimp larvae to bluefin tuna could be exposed to toxic chemicals for months or years to come (see page 22). So it would be useful to know whether it is even still there.

Clues about how long the oil might persist came from a study published on 19 August $^{1}$, which provided the first detailed map of the plume. Although "you hear rumours of what people have found and you read things in the newspaper", says Ben Van Mooy,

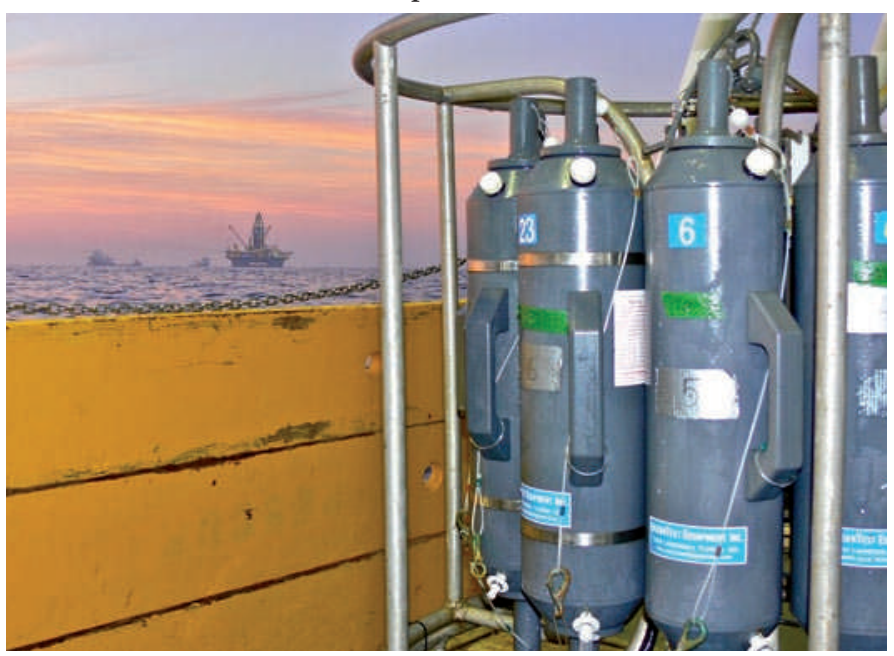

Clear, or present danger? Gulf samplers are struggling to track the oil plume. microbial activity. It seemed the microbes were making quick work of the plume - at least in late May to early June, when the measurements were taken.

John Kessler, a chemical oceanographer at Texas A\&M in College Station, points out that both studies are snapshots based on data that
1,100 metres and has drifted more than 130 kilometres away from where it was initially detected ${ }^{4}$. "The plume is not gone, it's moved," says Samantha Joye, a biogeochemist at the University of Georgia in Athens. Joye is at sea on a two-ship operation in a different part of the Gulf from Hazen's vessels, and is using dif- an oceanographer at the Woods Hole Oceanographic Institution (WHOI) in Massachusetts and a co-author on the study, there has been little in the scientific literature to back up the reports ${ }^{3}$ before now.

Van Mooy and his colleagues measured oxygen levels and hydrocarbon concentrations in the Gulf in late June. They found a continuous drifting oil mist more than 35 kilometres long at a depth of about 1,100 metres, and also discovered that oxygen levels in the water were not dropping substantially ${ }^{1}$. The team interpreted this to mean that microbes were not consuming much oxygen, and therefore not significantly degrading the oil. On the basis of their findings, the researchers concluded that the plume had "persisted for months without substantial degradation", leading them to suggest in their paper that the subsurface oil could linger for months to come.

A second study on the plume ${ }^{2}$, led by Terry Hazen, a microbial ecologist from Lawrence Berkeley National Laboratory in Berkeley, California, was published on 24 August. Although Hazen's team measured stable oxygen levels, the group also found oil-eating microbes of the order Oceanospirillales and saw intense are months old. "We shouldn't extrapolate the entire plume based on a few different hydrocarbons that were measured," he says.

Media reports got even murkier when messages about the two Science papers were conflated with emerging details about the current status of the plume. Hazen notes, for example, that the research cruise he is now overseeing has been trying unsuccessfully to trace the plume for several weeks. He believes that the oil has now "all dissipated and degraded". "We would love to find it to do more research on it," he says, "but it's not there."

"I find that difficult to believe," counters David Valentine, a geomicrobiologist at the University of California, Santa Barbara. During a cruise in June, Valentine found that oxygen levels in the plume were variable, indicating that there was a subtle balance between microbial respiration and ocean mixing. The upshot is that oxygen levels alone are not enough to calculate rates of oil degradation, he says - not least because some hydrocarbons break down much more quickly than others.

Other researchers at work in the Gulf insist that the plume is still lurking at a depth of ferent instruments that are "clearly picking up the plume", she says.

Working through these complexities will require extensive sampling over the coming months, says James Hollibaugh, a microbial ecologist at the University of Georgia. "It's not something we're going to figure out in the next week or two." Hazen's team, for example, is setting out 'bug traps' at various depths to see what kinds of microbe are there, and whether they are feasting on oil. The group is also drilling cores around the well head and near the path of the plume to determine whether oil is being trapped in the sediment.

Van Mooy says that the episode highlights the need for open lines of communication between everyone studying the spill. In the frantic scramble to gather data, there has been too little coordination between the government and academic scientists to assess exactly what measurements are needed, adds Joye. "You've had this sort of panicked mania going on of random sampling that may or may not provide the data that we need to really assess the situation."

This week, the multi-agency Unified Command, which is coordinating response efforts to the Deepwater Horizon spill, will be holding a series of meetings with academic scientists to develop a sampling plan to assess the oil remaining in the Gulf. "That is leaps and bounds above anything I've seen up to this point, and a sign of a more concerted response," says Valentine.

"If we're going to find out about this plume in this emergency," adds Van Mooy, "we all need to start talking to each other somehow."

\section{Amanda Mascarelli}

1. Camilli, R. et al. Science doi:10.1126/science.1195223 (2010)

2. Hazen, T. C. et al. Science doi:10.1126/science.1195979 (2010).

3. Schrope, M. Nature 465, 274-275 (2010).

4. Mascarelli, A. Nature doi:10.1038/news.2010.420 (2010).

See www.nature.com/oilspill for more on the oil spill. 